\title{
Aspects of finite element modeling of strengthened RC walls with opening
}

\section{Marcos A. Silvaa* (D), Rafael A. Sanabria Díaz ${ }^{a}$ (D), Leandro Mouta Trautwein ${ }^{a}$ (D) , Luiz C. Almeida ${ }^{a}$}

aDepartamento de Estruturas, Faculdade de Engenharia Civil, Arquitetura e Urbanismo, Universidade Estadual de Campinas, 224 Saturnino de Brito, Campinas, Brasil. Email: marcosasilva@live.com,r163449@dac.unicamp.br, leandromt@fec.unicamp.br, almeida@fec.unicamp.br

* Corresponding author

https://doi.org/10.1590/1679-78256572

\begin{abstract}
Fiber-reinforced polymers are materials used to recover/strengthen reinforced concrete structures load capacity. This material exhibits good mechanical properties with low self-weight. This work performed a series of nonlinear finite element analyses in one-way (OW) wall panels with a central cut-out opening, strengthened using carbon fiber-reinforced polymer (CFRP). The experimental tests conducted by Mohammed et al. (2013) were used as a benchmark. The numerical simulations were carried out in the commercial code ATENA, in which the material and geometrical nonlinearities were accounted. As a result, the numerical models reasonably predicted the ultimate load of the walls, and all models presented a crack pattern similar to the experimental tests, verifying that the CFRP addition caused a more distributed crack pattern. The results obtained in this work revealed that CFRP strengthening caused $24-50 \%$ enhancement of the ultimate load. Additional models were carried out to extend the numerical results and proposed a new equation that can be used to predict the ultimate load of OW walls with and without CFRP strengthening.
\end{abstract}

\section{Keywords}

Numerical analysis, finite element method, wall, panel, reinforced concrete, CFRP strengthening

\section{Graphical Abstract}

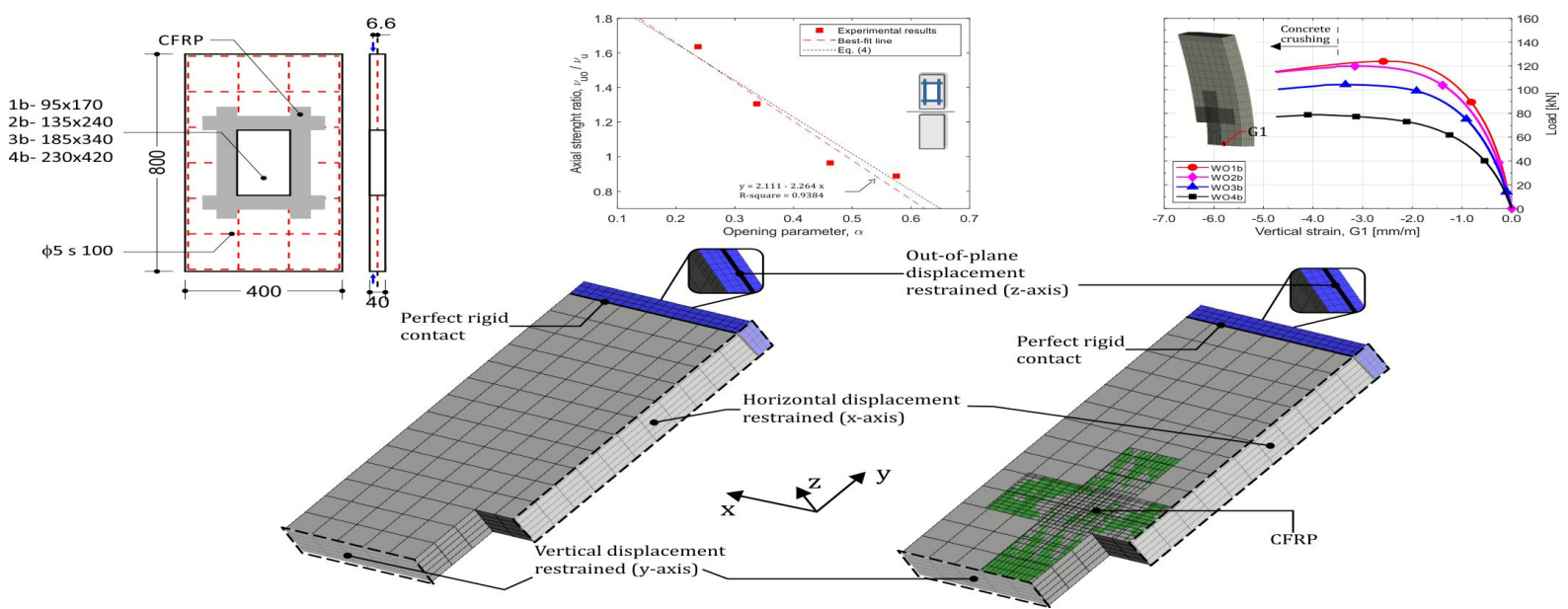

Received May 22, 2021. In revised form October 05, 2021. Accepted October 18, 2021. Available online October 20, 2021 https://doi.org/10.1590/1679-78256572

(9) Latin American Journal of Solids and Structures. ISSN 1679-7825. Copyright @ 2021. This is an Open Access article distributed under the terms of the Creative Commons Attribution License, which permits unrestricted use, distribution, and reproduction in any medium, provided the original work is properly cited. 


\section{INTRODUCTION}

It is known that small cut-out openings in reinforced concrete $(\mathrm{RC})$ wall panels have no particular effect on the load capacity. Although this statement seems a consensus among the researchers, Popescu et al. (2015) explained that the existing literature is not clear the limits classifying an opening as small. Standards codes such as CEN (2004) and AS 3600 (2018) recommend that an opening can be ignored if its height is less than $1 / 3$ of the wall height or its area is lesser than $1 / 10$ of the wall area. On the other hand, Brazilian provision codes, such as NBR 16055 (2012), recommends that openings with dimensions smaller than twice the wall thickness can be dismissed from any further verification or strengthening.

The removal of a large amount of concrete and reinforcement can produce undesirable effects on RC panels. According to Popescu et al. (2015), an opening may change the wall stress distribution, influencing its structural behavior. As a consequence, some studies have reported reductions in bearing capacity and modification of the failure modes. Guan et al. (2010) reported the opening length is more significant to the wall strength than its height, which contrasts with the fact some standards do not take into account the length as a parameter. Furthermore, Fragomeni et al. (1994) noticed the concrete portions above and below openings behave similarly to beam strips, whereas lateral edges are similar to columns.

Saheb and Desayi (1990) performed one of the first systematic experimental studies on one-way (OW) walls with opening, assuming that the load capacity of a wall with an opening $\left(p_{u o}^{c}\right)$ is a linear reduction of an identical solid wall load capacity $\left(P_{u}^{c}\right)$. Therefore, they introduced Eq. (1) based on an empirical analysis for predicting the ultimate load of walls with an opening, in which the linear coefficients $k_{1}=1.25$ and $k_{2}=1.22$ were originated from experimental curve fitting. The identical solid wall's load capacity $\left(p_{u}^{c}\right)$ follows from ACl 318 (1977). The opening parameter $\alpha$ takes into account the horizontal dimension and projection of the opening, also its position within the wall (see Figure 1), calculated according to Eq. (2).

$P_{u o}^{c}=\left(k_{1}-k_{2} \cdot \alpha\right) \cdot P_{u}^{c}$

$\alpha=\frac{L_{0} \cdot t_{w}}{L \cdot t_{w}}+\frac{a}{L}$

In the following years, other researchers made their contribution by adjusting the parameters of Eq. (1) according to newly obtained data, where are worthy mention works carried out by Doh and Fragomeni (2006), Guan et al. (2010), Mohammed et al. (2013). The effects of lateral restraints in two-way (TW) walls and high strength concrete were incorporated into the linear coefficients $k_{1}$ and $k_{2}$. Furthermore, Guan et al. (2010) proposed a modification on parameter $\alpha$, accounting for the number of openings, dimension and position towards the vertical direction.
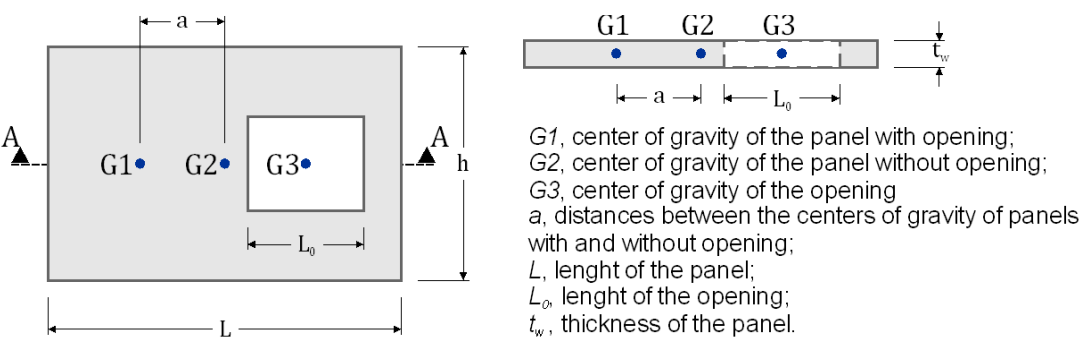

Figure 1 Geometric properties for calculating the parameter $\alpha$.

The externally bonded (EB) carbon fiber reinforced polymer (CFRP) provided well results by restoring or increasing the strength of several structural elements such as beams, columns, and slabs (Azevedo 2008, Florut et al. 2014). Its application on RC wall panels has shown to be able to reduce the effect of cut-out openings. Hansen et al. (2009) reported the advantages of this strengthening technique: low weight to high strength ratio, good mechanical properties, and easy application.

In the literature, the studies regarding strengthened RC wall panels are often related to retrofitting of structures damaged by seismic events where the shear forces are predominant. The benefits of strengthening shear walls with opening using FRP material are shown in several works (Li et al. 2013, Todut et al. 2015, Mosallam and Nasr 2017, Husain et al., 2019). A few investigations have focused on the structural behavior of strengthened self-bearing walls with 
openings. Among them, it can be highlighted experimental tests of Mohammed et al. (2011) on OW walls, and Lima et al. (2019) on both OW and TW walls.

As an outcome of their research, Mohammed et al. (2013) proposed Eq. (3)-(4) for predicting the load capacity of OW walls with openings, with and without CFRP strengthening, respectively. The equations were obtained by linear regression of the experimental data. It must be mention that Mohammed et al. (2013) used the same reference concrete strength for calculating the load capacity of all identical solid walls without opening $\left(P_{u}^{c}\right)$. Therefore, the linear coefficients were influenced not only by the opening but also by the difference of concrete strength between the tested specimen and the identical solid wall.

$$
\begin{aligned}
& P_{u o}^{c}=(1.227-0.803 \cdot \alpha) \cdot P_{u}^{c} \\
& P_{u o c}^{c}=(2.0765-2.1186 \cdot \alpha) \cdot P_{u}^{c}
\end{aligned}
$$

This paper performs a series of nonlinear finite element analysis (NLFEA) in OW wall panels with opening and CFRP strengthened, addressing the development of a methodology for analyzing the behavior of these structures. Two series of walls tested by Mohammed et al. (2013) were selected, including cases with and without strengthening. In addition, it proposes a new equation for predicting the load capacity of strengthened walls with a central opening based on the compression axial strength and parametric numerical analysis.

\section{Reference experimental tests}

The RC walls tested by Mohammed et al. (2013) had dimensions $800 \times 400 \times 40 \mathrm{~mm}$ with a central opening of different sizes, resulting in slenderness $\left(h / t_{w}\right)$ and aspect ratios $(h / L)$ of 20 and 2 , respectively. Figure 2 illustrates the geometry of typical RC walls studied in this paper. Loading and support steel plates were placed at the top and bottom edges to avoid premature cracking due to stress concentration. A uniform distributed load and the reaction acted eccentrically to the wall mid-plane $\left(t_{w} / 6\right)$, and the lateral edges were unrestrained, allowing the ow behavior. The openings had dimensions of $5 \%, 10 \%, 20 \%$, and $30 \%$ of the panel's area, identified by the numbers $1,2,3$, and 4 , respectively.

The walls were separated into two series, $A$ and $B$, having four specimens each. Series $A$ represented the not strengthened case, whereas series $B$ had the EB CFRP along with the edges of the openings, in both faces of the wall. The following nomenclature was adopted to identify the walls: WO1a - WO4a (series A) and WO1b - WO4b (series B), in which the number indicates the opening's size and the small-cap letter regards the belonging series. For instance, specimen WO2a refers to series A with the opening 2, and specimen WO3b refers to series B (strengthened) with the opening 3 .
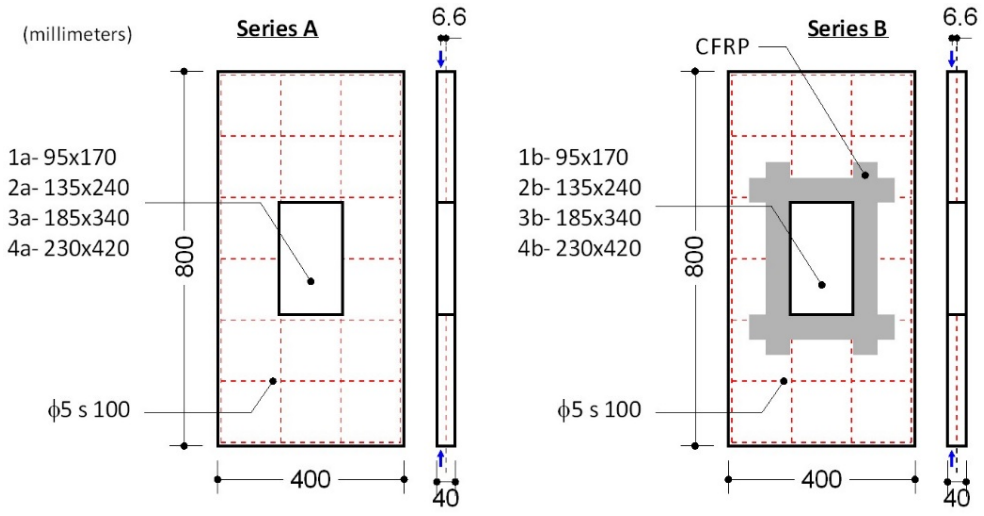

Figure 2 Dimensions and rebar layout.

A single reinforcement layer of $5 \mathrm{~mm}$ rebars was placed in the wall mid-plane preventing premature cracking due to creep and shrinkage, providing steel ratios of $0.005 \%$ and $0.009 \%$ in the vertical and horizontal directions. The average proof yielding strength and modulus of elasticity of the rebars were $478 \mathrm{MPa}$ and $205 \mathrm{GPa}$, respectively. The cylinder compressive strength $\left(f_{c}\right)$ was estimated according to Table 1 . The mean value of the tensile strength $\left(f_{t}\right)$, Young's modulus $\left(E_{c}\right)$ and Poisson's ratio $(v)$ of the concrete were $1.46 \mathrm{MPa}, 21 \mathrm{GPa}$, and 0.21 , respectively. Full details of the reference models can be found in Mohammed et al. (2011) and Mohammed et al. (2013). 
Table 1 Average compressive strength of concrete.

\begin{tabular}{cccc}
\hline Series A & $f_{c}$ (MPa) & Series B & $f_{c}$ (MPa) \\
\hline W01a & 15.99 & WO1b & 14.97 \\
W02a & 13.94 & WO2b & 17.08 \\
W03a & 15.57 & WO3b & 18.24 \\
W04a & 15.79 & W04b & 15.06 \\
\hline
\end{tabular}

For the walls with strengthening, the CFRP material was bonded along with the opening with a $60 \mathrm{~mm}$ width and $250 \mathrm{~mm}$ anchorage length initiated from the opening's corners. In cases where the anchorage length available was small, the CFRP was extended until the panel's edge. The experimental tests reported the load capacity, crack pattern, and failure mode of the wall panels. No information regarding the panel stiffness or the CFRP strain through the loading process was found in the reference paper to evaluate the structural behavior.

\section{Finite element modeling}

In this study, the NLFEA was performed using the computational programs ATENA (version 5.6.0) and GiD (version 10.0.9). ATENA, which has been developed by Červenka Consulting, is the core of the finite element processing and post-processing, with constitutive relationships capable of considering the material nonlinearities, such as tension and compression cracking, crushing, and yielding. The theory basis of ATENA is presented by Cervenka et al. (2020). GiD has been developed by the International Center for Numerical Methods in Engineering (CIMNE) and works as a pre-processor used to define the model properties and generate the finite element mesh. More information regarding GiD can be found in Coll et al. (2018).

The concrete nonlinear behavior is represented by the CC3DNonLinCementitious2 model implemented in ATENA. The concrete uniaxial constitutive law combines a fracture model for cracking (tension) with a plasticity model for concrete crushing (compression), as shown in Figure 3(a). In this case, the Rankine tensile criterion governs the fracture process based on a smeared crack approach that can be coupled with fixed and rotating crack models. In the tension softening, the current concrete tensile strength is a function of the crack width. The exponential crack opening law proposed by Hordijk (1991), depicted in Figure 3(b), was used to define the tension softening. Also, the simulations employ a refined crack band formulation proposed by Cervenka et al. (1995), in which the crack band's size derives from the element's projection in the direction of the crack.

The concrete crushing is based on the general formulation of Menétrey and Willam (1995) considering the failure surface's movement depending on the value of the strain hardening/softening parameter. Furthermore, the failure adopts a fictitious compression plane model that is normal to the direction of the compression principal stress. The strain is based on the equivalent plastic strain and the hardening/softening law is set up on the uniaxial compression test (see Figure 3(c)). In general, the plastic model is non-associated since the plastic flow is not perpendicular to the failure surface.

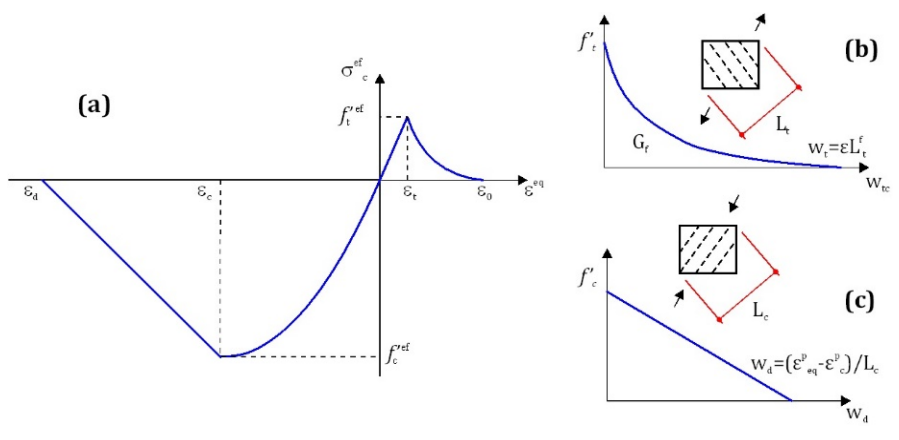

Figure 3 Constitutive model for concrete.

By taking advantage of the double symmetry condition ( $x$ and $y$ axis), the model covered $1 / 4$ of the original RC wall reducing the computational cost. Figure 4 represents typical models of strengthened and not strengthened wall cases with the corresponding boundary conditions. The loading plate was connected to the wall by a master-slave condition providing a perfect rigid contact. On top of the loading plate, the load was applied through a uniform vertical displacement ( $y$-axis) acting in an eccentric line $\left(t_{w} / 6\right)$. This line also had the out-of-plane displacement ( $z$-axis) restrained. Besides, vertical and horizontal displacements were restrained in the bottom and right edge of the model, respectively. 
Monitoring points recorded the displacement and strains at predefined locations which help to evaluate stiffness and stress distribution. The vertical reaction was taken on the bottom surface of the model.

The reinforcement layer was modeled considering a discrete approach using two-nodes truss elements, placed on the wall mid-plane. These elements were embedded in the concrete assuming perfect bond condition. The walls of series $B$ were modeled with EB CFRP along with the opening in both tension and compression faces. A perfect bond condition also linked the concrete with strengthening material.

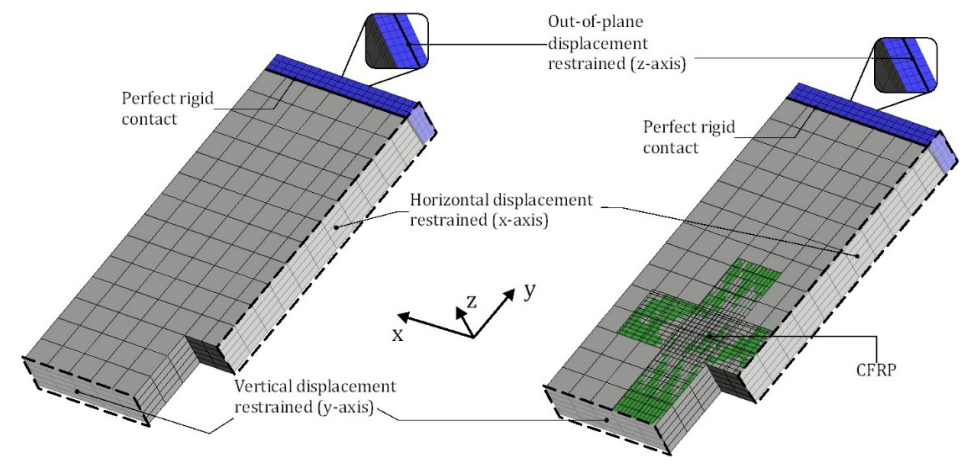

Figure 4 Typical model with mesh representation and boundary condition.

\subsection{Baseline analysis}

For solving the nonlinear system of equations, the iterative solution procedure employed the Newton-Raphson method limited to 30 iterations, tangent stiffness predictor, and line search technique. The convergence error tolerances were set $1 \%$ for displacement and force and $0.01 \%$ for energy. Besides, the conditional break criteria interrupted the processing if the error was above $10 \%$ for displacement and force equilibrium, and $100 \%$ for energy between incremental steps.

The baseline models used the constitutive material CC3DNonLinCementitious2, which combines fracture and plastic behavior of the concrete, and generates the basics parameters based on the fib-Model Code 2010. Table 2 summarizes the main concrete parameters adopted in the baseline analysis. This material was applied to solid elements CClsoBrick with linear ( 8 nodes) and quadratic formulation (20 nodes), tested in the next section regarding the mesh objectivity. Loading plates were modeled with an isotropic constitutive material CC3DElastlsotropic presenting linear-elastic behavior. This isotropic material adopted Young's modulus and Poisson's ratio, $210 \mathrm{GPa}$ and 0.3 , respectively, and was applied to solid elements CClsoBrick of 8 nodes.

The rebars constitutive material CCReinforcement assumed an elastic-perfectly plastic behavior, which was applied to truss elements (CClsoTruss) of 2 nodes. Young's modulus and yield strength of this material model were $205 \mathrm{GPa}$ and $478 \mathrm{MPa}$, respectively, with $2.52 \%$ ultimate strain.

Table 2 Main parameters adopted for the concrete's constitutive model.

\begin{tabular}{|c|c|c|}
\hline Parameter & Baseline analysis & Observation \\
\hline Compression strength $\left(f_{c}\right), \mathrm{MPa}$ & Table 1 & - \\
\hline Tension strength $\left(f_{t}\right), \mathrm{MPa}$ & $0.3\left(f_{c}+8\right)^{2 / 3}$ & fib Bulletin 65 (2010) \\
\hline Young's modulus $\left(E_{c}\right), \mathrm{MPa}$ & $21500\left(\left(f_{c}+8\right) / 10\right)^{1 / 3}$ & fib Bulletin 65 (2010) \\
\hline Poisson's ratio $(v)$ & 0.20 & - \\
\hline Fracture energy $\left(G_{f}\right), \mathrm{N} / \mathrm{m}$ & $73\left(f_{c}\right)^{0.18}$ & fib Bulletin 65 (2010) \\
\hline Tension soft. law & Exponential & Hordijk (1991) \\
\hline Crack model & Fixed direction & Cervenka et al. (1995) \\
\hline Onset non-lin. behavior, $\left(f_{c 0}\right) \mathrm{MPa}$ & $2.1 f_{\mathrm{t}}$ & - \\
\hline Comp. strength red. due to crack & 0.80 & Dyngeland (1989) \\
\hline Compression soft. law & Linear & - \\
\hline Critical plastic disp., $\left(w_{d}\right) \mathrm{mm}$ & 0.50 & van Mier (1986) \\
\hline
\end{tabular}




\section{Mesh discretization}

A mesh study was performed in the models of series A (not strengthened series), investigating mesh objectivity and result convergence. This study focused on the models WO1a and WO4a representing the cases with a small and large opening. The element's dimension varied according to Table 3 , and addressed the linear and quadratic shape functions in the CClsoBrick elements. The first letter of the mesh types stands for the shape function adopted: $L$ (linear) or $Q$ (quadratic). Due to the bending effect, the models adopted five layers of elements through the wall thickness.

Table 3 Mesh properties. The nomenclature used for the element's dimension (abc) in millimeters is illustrated in Figure 5.

\begin{tabular}{|c|c|c|c|c|}
\hline Mesh type & Total nodes & Total elements & Element dimension $(a b c)$ & Element type \\
\hline LA & 5454 & 4115 & $10 \times 10 \times 8$ & CClsoBrick8 \\
\hline LB & 1770 & 1200 & $20 \times 20 \times 8$ & CClsoBrick8 \\
\hline LC & 1116 & 700 & $30 \times 30 \times 8$ & CClsoBrick8 \\
\hline LD & 816 & 480 & $40 \times 40 \times 8$ & CClsoBrick8 \\
\hline QA & 20362 & 4115 & $10 \times 10 \times 8$ & CClsoBrick20 \\
\hline QB & 6426 & 1200 & $20 \times 20 \times 8$ & CClsoBrick20 \\
\hline QD & 2859 & 480 & $40 \times 40 \times 8$ & CClsoBrick20 \\
\hline
\end{tabular}
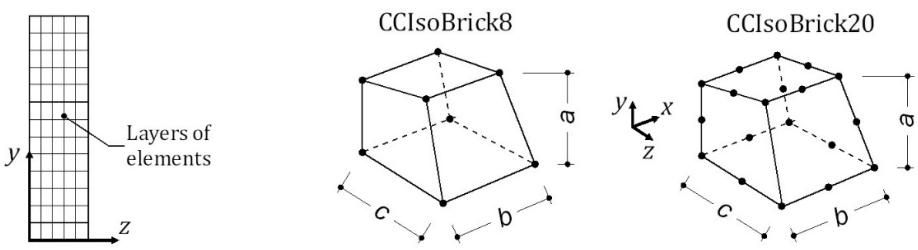

Figure 5 Finite element types and nomenclature used in Table 4.

The numerical response of out-of-plane displacement versus load is shown in Figure 6 for each mesh type. In the referred figure is also indicated the ultimate loads from the experimental tests (WO1a-100kN and WO4a-73.7kN), and the theoretical loads (WO1a-94kN and WO4a-53.1kN), calculated according to Eq. (1). The mesh types with linear interpolation elements presented a general trend (see Figures 6(a) and 6(c)), in which the ultimate loads converged with the mesh refinement. In turn, the discretization influenced these model's stiffness once the coarse mesh (LD) had the smallest out-of-plane displacement at the ultimate load. The mesh types with quadratic elements showed a reduced mesh sensitivity (see Figure $6(\mathrm{~b})$ and $6(\mathrm{~d})$ ) and all models presented similar stiffness.
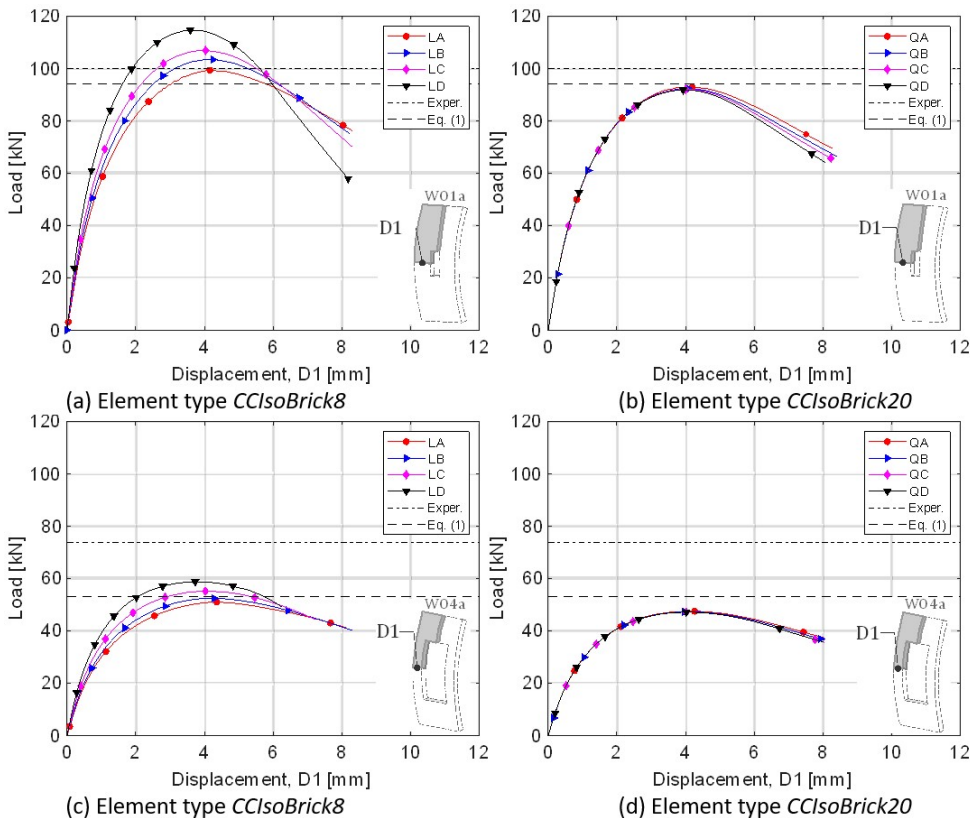

Figure 6. Comparison of load-displacement curves of meshes A to D with linear and quadratic elements. 
As expected, an increase in the opening's dimension caused a reduction of the ultimate load from models WO1a to WO4a. In the case of models WO1a, the ultimate load revealed good agreement with the experimental result and the theoretical prediction by Eq. (1). However, model WO4a resulted in a smaller strength than in the experimental test yet near the theoretical prediction. The fact the ultimate load is very sensible to the loading eccentricity may explain the results for opening number 4 since its reduction could be implied an increase in the experimental result. According to the simulations, the failure of wall panels was caused by excessive bending, which occurred in the softening regime (after reaching the ultimate load). In the models was verified concrete crushing and horizontal cracks in the column strip's half-height.

Based on the conducted analysis, the mesh type LC was chosen for further investigations because it incorporates the general behavior of OW walls, also presenting a reasonable agreement with ultimate loads. Table 4 shows the ultimate loads of the four walls belonging to the not strengthened case (series A).

Table 4 Load results of baseline analysis using mesh type LC.

\begin{tabular}{|c|c|c|c|c|c|}
\hline \multirow{2}{*}{ Wall } & \multicolumn{3}{|c|}{ Ultimate load (kN) } & \multirow{2}{*}{$\frac{\text { Model }}{\text { Experiment }}$} & \multirow{2}{*}{$\frac{\text { Model }}{\text { Eq.(1) }}$} \\
\hline & NLFE model & Experimental test & Eq. (1) & & \\
\hline W01a & 106.8 & 100.0 & 94.0 & 1.07 & 1.14 \\
\hline WO2a & 78.8 & 95.3 & 72.9 & 0.83 & 1.08 \\
\hline W03a & 69.4 & 85.0 & 65.6 & 0.82 & 1.06 \\
\hline \multirow[t]{3}{*}{ W04a } & 55.2 & 73.5 & 53.1 & 0.75 & 1.04 \\
\hline & & & Var. & 0.0193 & 0.0018 \\
\hline & & & S.d. & 0.1391 & 0.0419 \\
\hline
\end{tabular}

To evaluate and verify the numerical results, the cross-section strength of the column strip was estimated in terms of compression with biaxial bending. Each of the curves shown in Figure 7 represents the bending moment's envelope regarding axis $x$ and $z$, under the corresponding model's compression force. These envelopes take into account the mechanical properties of the cross-section and reinforcement layout. As shown in Figure 7(a), the discrete points representing biaxial bending from NLFEA are near the limits of the corresponding column-strip, meaning that the models' ultimate load is near the strength limit. The uniaxial bending tends to prevail as the opening size increases (see Figure $7(b)$ ).

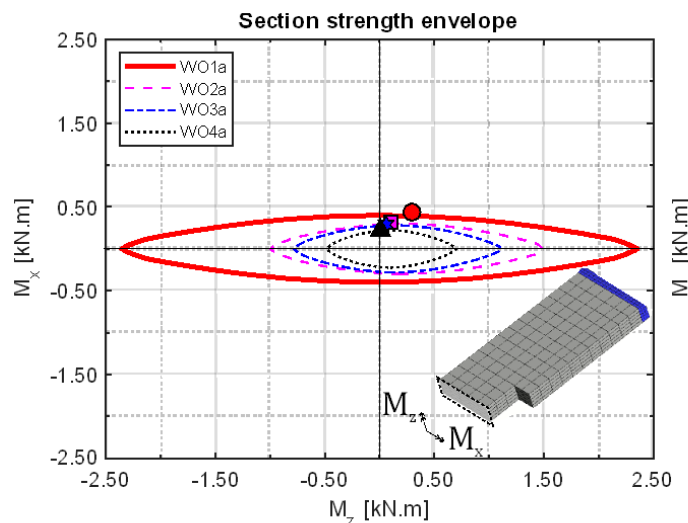

(a)

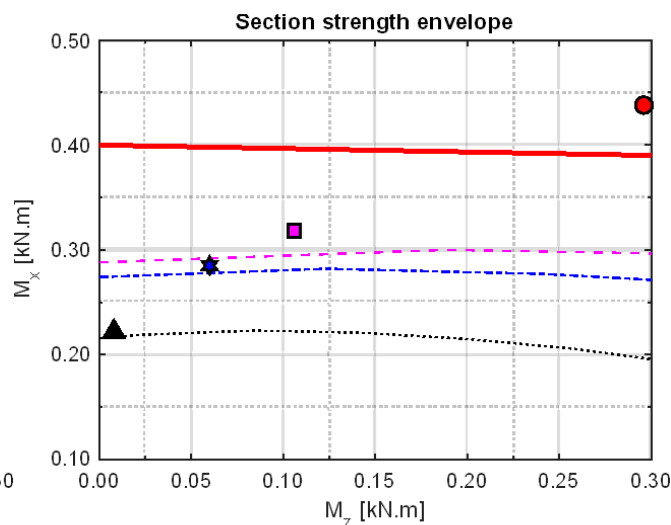

(b)

Figure 7 Cross-section's strength for compression with biaxial bending.

\section{CFRP strengthening modeling}

There are several approaches to simulate CFRP fabric in finite element analysis. Some of them are discussed in detail by Silva et al. (2021). In the present study, 2D membrane elements working in a plane-stress state were used. This type of element can reproduce compression and tension and has not out-of-plane flexural stiffness. The material constitutive model CCCombinedMaterial was employed to modeling the CFRP fabric, which can combine brittle and ductile behavior inside one composite material. The brittle behavior corresponds to the epoxy resin involving the carbon fibers, which, in turn, exhibit a linear behavior until its rupture. Using this approach, the material model considers the orthotropic effect caused by the unidirectional fibers. 
Some mechanical parameters of the strengthening material might be hard to define since not all of them are always included in the manufacturer's catalog, for example the fracture energy and the plastic strain at the peak stress. In this paper, the developed models adopted the materials parameters suggested by Sajdlová (2016). Furthermore, the mechanical parameters were obtained from Mapei (2014) and are listed in Table 5. According to Mohammed et al. (2011), the experiment showed full composite action of concrete and CFRP until the concrete reaches crushing in compression or the CFRP rupture in tension. Furthermore, as the tensile strength of the adhesive is usually higher than in the concrete, a thin layer of concrete will remain on the CFRP. In the developed models, the concrete and CFRP connection was admitted perfectly rigid using a master-slave condition where the nodes from the CFRP mesh (slave) are coupled with the nodes belonging to the concrete mesh (master). This condition assumed a critical distance of $0.5 \mathrm{~mm}$ between two nodes for connecting them directly. The ones that have larger distances are tied together using generalized complex constraints.

Table 5 Properties of the strengthening material.

\begin{tabular}{cccc}
\hline \multicolumn{1}{c}{ Epoxy resin } & & \multicolumn{1}{c}{ CFRP fabric } \\
\hline Young's modulus, MPa & 2500 & Young's modulus, MPa \\
Tension strength, MPa & 30 & Tension strength, MPa \\
Compression strength, MPa & 65 & Ultimate strain & 252000 \\
Thickness, $\mathrm{mm}$ & 0.5 & Thickness, mm & 0.02 \\
\hline
\end{tabular}

Two situations were analyzed regarding the carbon fibers' compression strength. The first one considered the fibers able to support compression, whereas the second had its compression strength neglected. Figure 8(a) presents the loaddisplacement curves of these two situations, where the models WO1b* and WO4b* represent fibers not supporting compression. It can be noticed a significant reduction of the load capacity when neglecting the compression strength of the carbon fibers. Since the failure occurs due to excessive bending with concrete crushing, the compression strength of the CFRP absorbs part of the resultant force and enhances the load capacity of the model. Figure 8(b) shows the vertical strain in the critical section of strengthened models considering the fibers able to support compression. It was noticed all models experienced concrete crushing near the ultimate load.

Table 6 summarizes the load capacity of the strengthened walls. It can be observed that the numerical loads are closer to the experimental ones for the panels with larger openings.

Table 6 Load capacity of specimens on series B.

\begin{tabular}{|c|c|c|c|c|c|}
\hline \multirow{2}{*}{ Model } & \multicolumn{2}{|c|}{ Ultimate load (kN) } & \multicolumn{2}{|c|}{ Axial strength $\left(P_{u} / f_{c} A_{c}\right)$} & \multirow{2}{*}{$\frac{N L F E A}{E x p .}$} \\
\hline & Model (NLFEA) & Experimental test & Model (NLFEA) & Experimental test & \\
\hline W01b & 123.8 & 149.9 & 0.5158 & 0.6246 & 0.83 \\
\hline WO2b & 119.8 & 139.1 & 0.4379 & 0.5084 & 0.86 \\
\hline WO3b & 104.2 & 108.0 & 0.3578 & 0.3709 & 0.96 \\
\hline \multirow[t]{3}{*}{ WO4b } & 78.9 & 82.0 & 0.3266 & 0.3394 & 0.96 \\
\hline & & & & Var. & 0.0050 \\
\hline & & & & S.d. & 0.0707 \\
\hline
\end{tabular}

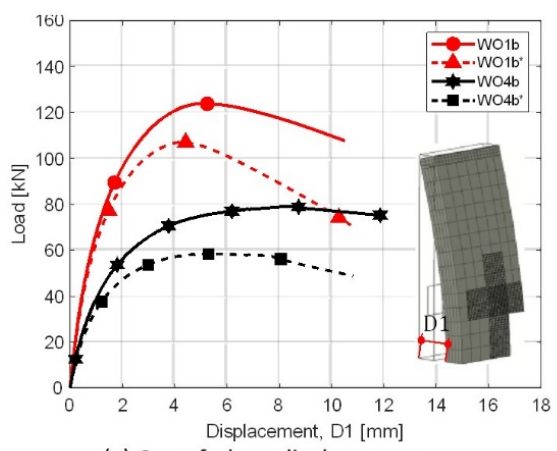

(a) Out-of-plane displacement

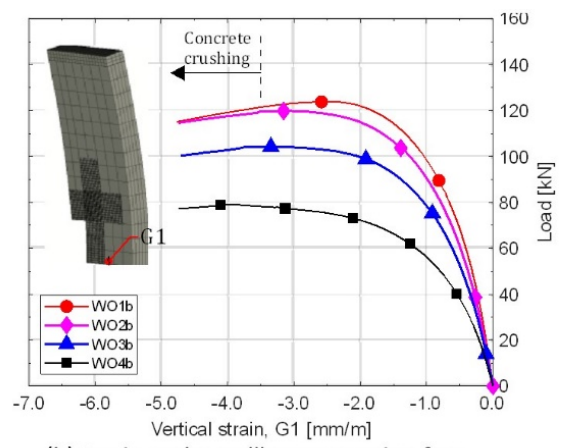

(b) Strain at the wall's compression face

Figure 8 Structural behavior of strengthened models. 
Figure 9 shows the axial wall strength as a function of the opening size. Compared to the not strengthened case (series A) results, the addition of CFRP enhanced by $24-50 \%$ the axial strength of the walls. According to Mohammed et al. (2011) results, the wall with the opening size number 1 had the largest enhancement (the ultimate load increased by 50\%). In contrast, the NLFEA revealed that the wall with the opening size number 4 was the most improved by the strengthening, achieving $43 \%$ of enhancing. By analyzing the results presented in Figure 9, it is noticed a general trend in which the axial strength is inversely proportional to the wall opening size. This trend agrees with the strength of materials' theory once the cross-section of the column strips, which bears the load, is reduced by increasing the opening size. However, the comparison of the axial strengths of openings 1 and 2 in experimental series A shows that the larger cross-section (opening size 1) achieved a lower load capacity, which can be considered unusual if the boundary conditions and load conditions are identical for both panels.

Lima (2016) warned about the difficulties encountered in experimental tests of concrete walls, which could explain the discrepancy observed in the specimen with opening size 1. According to Lima (2016), difficulties arise in obtaining the desired eccentricity $\left(t_{w} / 6\right)$ due to uneven wall thicknesses along the four edges and in each corner of the panel as well as the position of the top steel rod which might not be properly located at the required eccentricity $\left(t_{w} / 6\right)$.

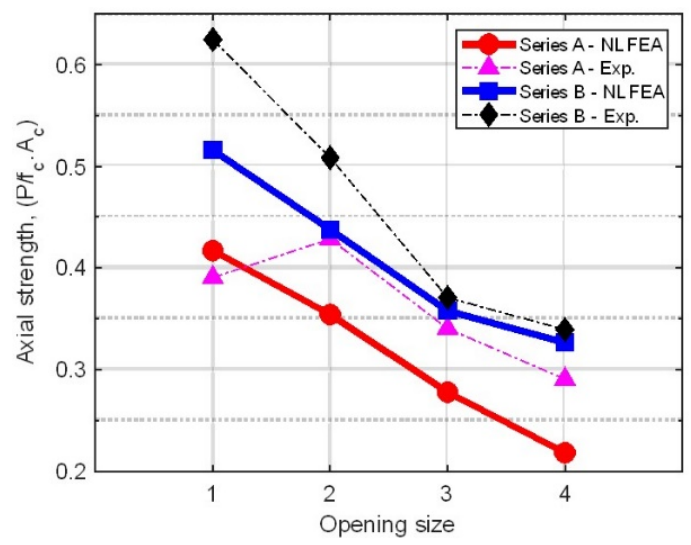

Figure 9 Axial compression strength of the series A and B (strengthened).

The evolution of the strain in the tension face was assessed in the numerical models. Figure 10(a) shows the evolution of the horizontal strain above the opening. A reduction of the strain, that coincided with the rise of the first vertical cracks, can be noticed. In the column strip, the cross-section remained compressed until roughly $87 \%$ of the ultimate load (see Fig. 10(b)). The CFRP presence limited the crack opening and altered the strain path through the wall, reflecting an increase of ductility during softening and well-distributed cracks. Considering the mean tensile strength of the concrete (1.46 MPa) and the mean Young's modulus (21 GPa), a crack initiates when the strain is around $0.7 \%$, therefore in the strengthened models, the horizontal cracks of G3 point initiate near the ultimate load.

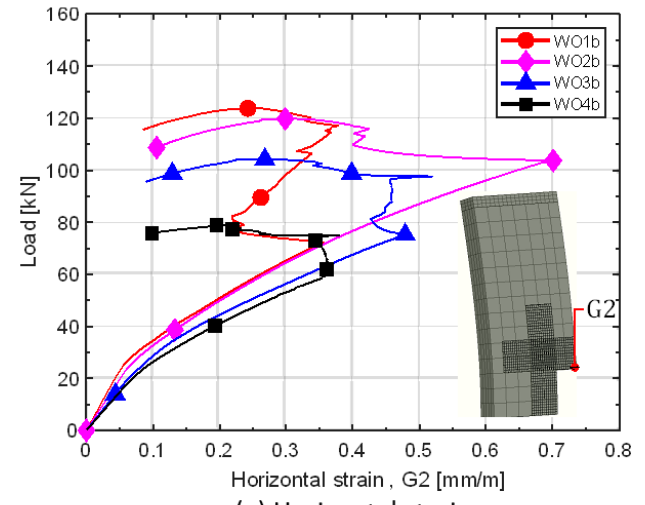

(a) Horizontal strain

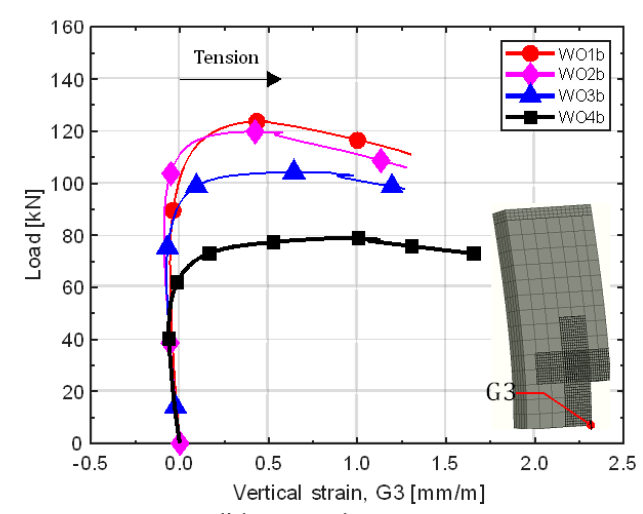

(b) Vertical strain

Figure 10 Concrete strains measures in the wall's tension face.

\section{Proposed Equation}

Equation 1 presumes that the load capacity with a central opening can be calculated as a function of the capacity of an identical solid wall and the opening parameter $\alpha$. The ultimate load can be divided by the gross cross-section area $\left(A_{c}\right)$ 
and the compressive strength $\left(f_{c}\right)$ to isolate the effect of the opening in the capacity. Hence, the concrete compression strength influence resulting from specimens with different concrete strength classes can be removed from this analysis by using the axial strength instead of the ultimate load. Table 7 summarizes the results obtained from series $A$ and $B$ regarding the experimental tests and the NLFEA.

Table 7 Strength summary of the analyzed walls.

\begin{tabular}{|c|c|c|c|c|c|c|c|c|c|}
\hline \multirow{2}{*}{ Wall } & \multirow{2}{*}{$\begin{array}{c}\text { Compression } \\
\text { Strength, } \mathrm{f}_{\mathrm{c}}(\mathrm{MPa})\end{array}$} & \multirow{2}{*}{$\begin{array}{c}\text { Opening } \\
\text { Parameter, } \alpha\end{array}$} & \multirow{2}{*}{$\begin{array}{l}\text { Reference solid } \\
\text { wall, } \mathrm{P}_{\mathrm{u}}^{+}(\mathrm{kN})\end{array}$} & \multicolumn{3}{|c|}{ Ultimate load, $\mathrm{P}_{\text {uо }}(\mathrm{kN})$} & \multicolumn{3}{|c|}{ Axial strength $\left(P_{u} / f_{c} A_{c}\right)$} \\
\hline & & & & NLFEA $^{1}$ & Eq. $(1)^{2}$ & Exper. $^{3}$ & NLFEA $^{1}$ & Eq. $(1)^{2}$ & Exper. $^{3}$ \\
\hline W01a & 15.99 & 0.2375 & 97.90 & 106.8 & 94.0 & 100.0 & 0.4174 & 0.3675 & 0.3909 \\
\hline W03a & 15.57 & 0.4625 & 95.66 & 69.4 & 65.6 & 85.0 & 0.2786 & 0.2633 & 0.3412 \\
\hline wo4a & 15.79 & 0.5750 & 96.83 & 55.2 & 53.1 & 73.5 & 0.2185 & 0.2102 & 0.2917 \\
\hline Wo1b & 14.94 & 0.2375 & 92.30 & 123.8 & - & 149.9 & 0.5169 & - & 0.6258 \\
\hline WO3b & 18.24 & 0.4625 & 109.91 & 104.2 & - & 108.0 & 0.3570 & - & 0.3701 \\
\hline WO4b & 15.06 & 0.5750 & 92.94 & 78.9 & - & 82.0 & 0.3274 & - & 0.3403 \\
\hline
\end{tabular}

† - Calculated according to ACI 318 (1977), 1 - Value obtained from the developed models, 2 - Calculated according to Saheb and Desayi (1990), 3 - Reference experimental result from Mohammed et al. (2013)

In Figure 11, the axial strength ratio (axial strength of wall with central opening divided by an identical solid wall) versus the opening parameter $\alpha$ is plotted for the experimental and numerical results. The best-fit data curves, calculated by the least square method, are also included in each plot. Figures $11(\mathrm{a})$ and $11(\mathrm{~b})$ show the experimental results by Mohammed et al. (2013) for series A and B, respectively, in which can be observed a linear trend as the opening increases; however, the best-fit curves slightly diverge from linear coefficients of Equations (3) and (4). As shown in Figure 11(b), Equation (4) may overestimate the axial strength capacity when the opening parameters $\alpha$ is higher than 0.25 .

The results from the numerical models are plotted in Figures $11(\mathrm{c})$ and 11(d), with the best-fit curves. For series $B$ (strengthening walls), additional models were carried out with two other opening sizes (with $\alpha=0.15$ and $\alpha=0.7$ ). The best-fit curves equations are presented in Equations (5) and (6), for not strengthened and strengthened models, respectively. In comparison with equations (3) and (4), it can be noticed that the proposed equations are conservative. Proposed equation tends to diverge from Equation (3) when the opening is increasing in series A; this pattern, however, is altered in series $B$ where the same trend is now observed when the opening is reducing, compared to Equation 4.

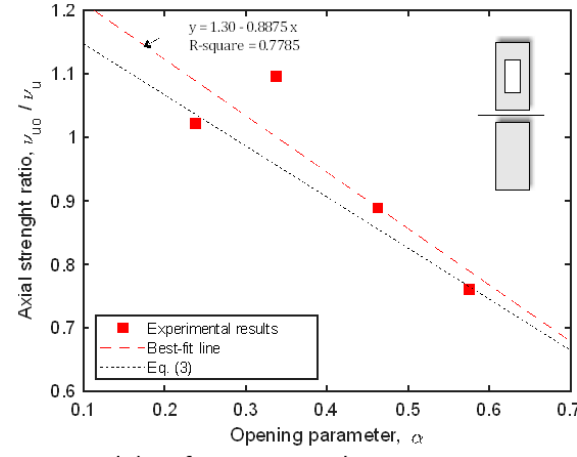

(a) Ref. exper. results - Series A

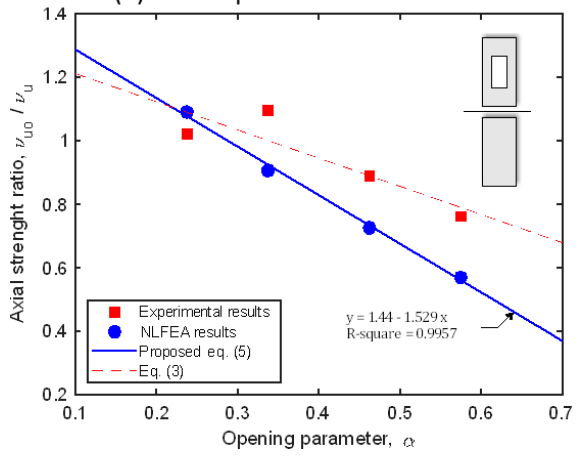

(c) Numerical results - Series A

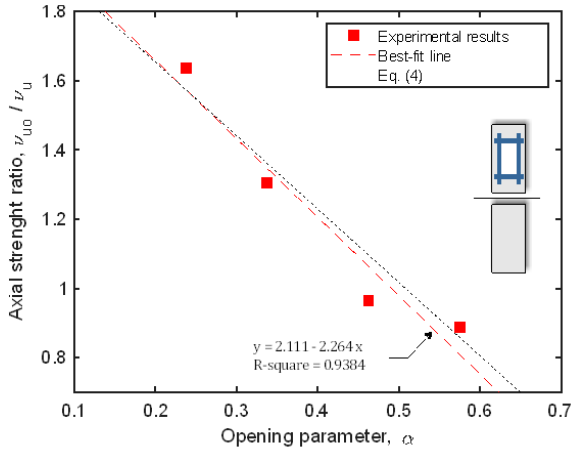

(b) Ref. exper. results - Series B

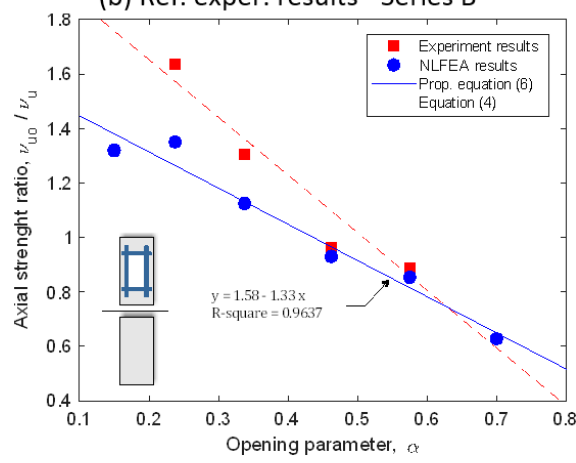

(d) Numerical results - Series B

Figure 11 Curve fitting of the axial strength for a varying opening size. 
$v_{u o}=(1.44-1.529 \cdot \alpha) \cdot v_{u}$

$v_{u o c}=(1.58-1.33 \cdot \alpha) \cdot v_{u}$

\section{Crack pattern}

In the RC walls, cracking initiated vertically above the opening and followed towards the loading edge. As the outof-plane displacement of the panel increased, horizontal cracks appeared in the column strip, originated in the lateral side, and followed towards the opening. In the cases with openings numbers 1 (see Figure 12(a)), the vertical cracks were near the vertical axis of symmetry representing the middle span. However, with openings number 4 (see Figure 12(b)), the vertical cracks were near the opening's corner, which indicates a change in the stress path.

Upon examination of Figure 12, the EB CFRP caused a more distributed cracking pattern. In turn, the crack opening of the column strip, outside the CFRP region, increased at the ultimate load. All models failed due to concrete crushing caused by excessive bending of the column strip, which happened throughout the softening stage for the not strengthened cases (series A), and at the ultimate load for the strengthened case (series B). Besides, Mohammed et al. (2011) reported the strengthened panels maintained full composite action of concrete and FRP until the concrete reaches crushing in compression or the FRP fails in tension.

Figure 13 shows the crack pattern of the experimental tests after failure reported by Mohammed et al. (2011). The authors explained that the cracks initiated vertically, above and below the opening, and followed towards the loading and reaction lines. Besides, the major horizontal cracks that caused the failure of the walls were formed at the column strips.

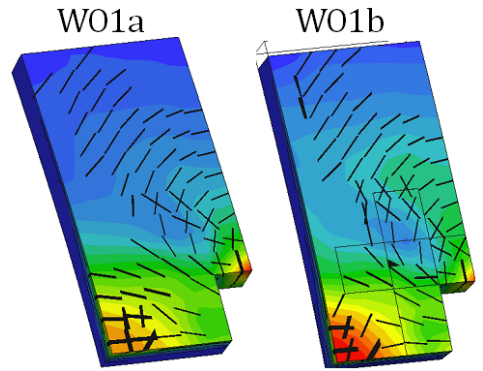

(a) Opening size number 1

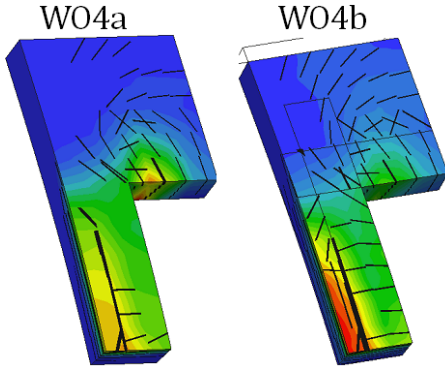

(b) Opening size number 4

Figure 12 Crack pattern of numerical models for the ultimate load.
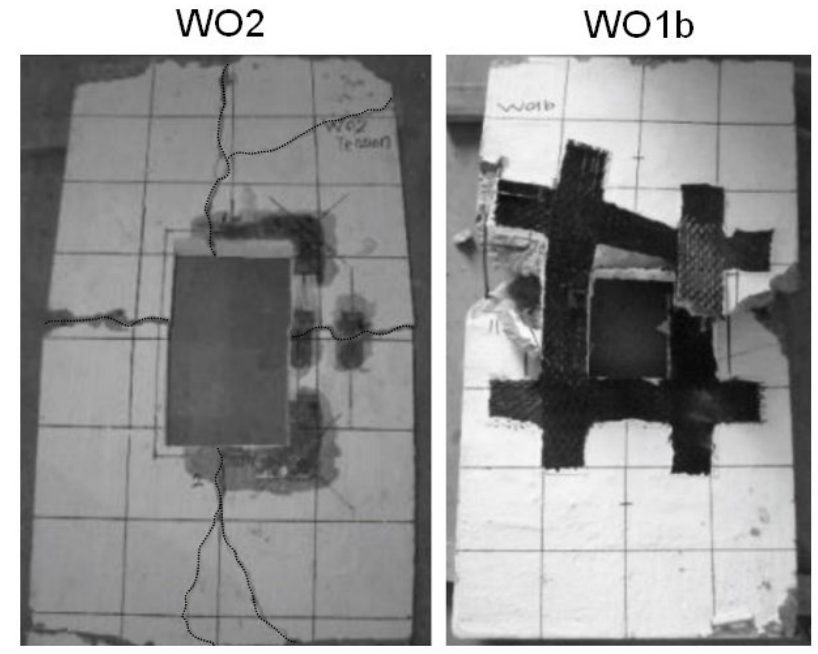

Figure 13 Crack pattern at failure based on Mohammed et al. (2011).

\section{Conclusions}

The following conclusions can be drawn from the NLFEA of the wall with a central opening:

- Series A: 
The models were able to reproduce reasonably the ultimate load of experimental test, thus the accuracy increased when compared with the theoretical formulation (Eq. (1)) proposed by Saheb and Desayi (1990). A further investigation showed the developed models reached the load capacities consistent with the analytical method, using the compression with biaxial bending envelope of the cross-section. In addition, it was noted that the biaxial bending is significant for the small openings, but not for large openings. Despite Mohammed et al. (2011), Mohammed et al. (2013) and Lima et al. (2016) haven't discussed the walls' stiffness, this work presented load-displacement curves for each RC wall from numerical analysis. On average, the out-of-plane displacement was $4 \mathrm{~mm}$ at the ultimate load, and the failure occurred in the softening regime. All not strengthened models failed due to excessive bending with a crack pattern similar to the experimental tests. Equation (5) was proposed in which considers the axial strength with an update of the linear coefficients $k$.

\section{- $\quad$ Series B (CFRP strengthened)}

The ultimate load increased towards the experimental results when the carbon fibers were considered able to withstand compression. Overall, the strengthening material improved by $24-50 \%$ the load capacity in the numerical models. A higher increase occurred in the model with a large opening (opening number 4). Besides, the strengthening caused more sparse cracks with limited crack opening, below the CFRP. The failure continued taking place in the column strip due to excessive bending, and the concrete crushing occurred near the ultimate load, reducing the softening regime. Equation (6) was introduced, in which agrees with the linear pattern of the axial strength ratio from both numerical and experimental results, considering the studied opening size range.

\section{Acknowledgments}

The authors would like to express their gratitude to the Coordenação de Aperfeiçoamento de Pessoal de Nível Superior (CAPES) and the Structural Modeling and Monitoring Laboratory (LABMEM) of the University of Campinas (UNICAMP) for supporting this research. Website: http://www.fec.unicamp.br/ labmem/

Author's Contribuitions: Conceptualization, MA Silva; Methodology, MA Silva and LC Almeida; Formal analysis, MA Silva and RAS Díaz; Writing - original draft, MA Silva; Writing - review \& editing, RAS Díaz, LC Almeida and LM Trautwein; Supervision, LC Almeida; Resources, LC Almeida and LC Trautwein.

Editor: Pablo Andrés Muñoz Rojas

\section{References}

ACI 318 (1977), Building Code requirements for structural concrete and commentary, MI, USA.

AS 3600 (2018), Concrete structures, Sydney, Australia.

Azevedo, D.M.M. (2008), "Reforço de estruturas de betão com colagem de sistemas compósitos de CFRP - Recomendações para dimensionamento", Dissertation, Universidade do Porto, Porto, Portugal.

CEN (2004), Design of concrete structures - Part 1.1: General rules and rules for buildings, Brussels, Belgium.

Cervenka, V., Pukl, R., Ozbolt, J. (1995), "Mesh sensitivity effects in smeared finite element analysis of concrete fracture", Fracture Mechanics of Concrete Structures. 1387-1396.

Cervenka, V., Jendele, L., Cervenka, J. (2020), ATENA program documentation, Part 1, Cervenka Consulting, Prague, Czech Republic.

Coll A, Ribó R, Pasenau M, Escolano E, Perez JS, Melendo A, Monros A, Gárate, J. (2018). GiD v.14 Reference Manual [pdf]. [accessed 2020 May 25]. www.gidhome.com

Doh, J., Fragomeni,S. (2006), "Ultimate load formula for reinforced concrete wall panels with openings", Advances in Structural Engineering. 9, 103-115.

Dyngeland, T. (1989), "Behavior of reinforced concrete panels", Dissertation, Trondheim University, Norway.

fib Bulletin 65, 2010. Model code 2010 - final draft, vol. 1; 2012. 
Floruţ, S.-C., Sas, G. Popescu, C. Stoian, V. (2014), "Tests on reinforced concrete slabs with cut-out openings strengthened with fibre-reinforced polymers", Composites Part B: Engineering.66, 484-493.

Fragomeni, S., Mendis, P., Grayson, W. (1994), "Review of reinforced-concrete wall design formulas", ACI Structural Journal. 91, 521-529.

Guan, H., Cooper, C. Lee, D-J (2010), “Ultimate strength analysis of normal and high strength concrete wall panels with varying opening configurations", Engineering Structures. 32, 1341-1355.

Hansen, C.S., Sas, G. Täljsten, B. (2009), "Tests on reinforced concrete slabs with cut-out openings strengthened with fibrereinforced polymers", 4th International Conference on Advanced Composites in Construction, Great Britain.

Hordijk, D.A. (1991), "Local approach to fatigue of concrete", Ph.D. Thesis, Technische Universiteit Delft, Delft, Netherlands.

Husain, M., Eisa, A.S., Hegazy, M.M. (2019), "Strengthening of reinforced concrete shear walls with openings using carbon fiber-reinforced polymers", Journal of Advanced Structural Engineering. 11, 488-504

Li, B., Qian, K., Tran, C.T.N. (2013), "Retrofitting earthquake-damaged RC structural walls with openings by externally bonded FRP strips and sheets", Journal of Composites for Construction. 17, 259-270.

Lima, M., Doh, J., Hadi, M., Miller, D. (2016), "The effects of CFRP orientation on the strengthening of reinforced concrete structures", The Structural Design of Tall and Special Building. 25(15), 759-784.

Lima, M. (2016), "Experimental and Numerical Study of RC Walls with Opening Strengthened by CFRP", Ph.D. Thesis, Griffith University, Australia.

Lima, M., Doh, J., Hadi, M.N.S. (2019), "Experimental Study on RC Walls with opening Strengthened by Externally Bonded CFRP", Journal of Composites for Construction. 23(2).

Mapei (2014), Specifications of application of composite materials. https://cdnmedia.mapei.com/docs/global-technicalspecification/application-of-composite-materials.pdf?sfvrsn=75a5b37f_12

Menétrey, P., Willam, K.J. (1995), “Triaxial failure criterion for concrete and its generalization”, Structural Journal.92, 311-318.

Mohammed, B.S., Ean, L., Hossain, K.M.A. (2011), “CFRP composites for strengthening of reinforced concrete walls with openings", International Journal of Engineering Research and Applications. 1, 1841-1852.

Mohammed, B., Ean,L., Malek, M. (2013), "One way RC wall panels with openings strengthened with CFRP”, Construction and Building Materials. 40, 575-87.

Mosallam, A.S., Nasr, A. (2017), "Structural performance of RC shear walls with post-construction openings strengthened with FRP composite laminates", Composites Part B: Engineering.115, 488-504.

NBR 16055 (2012), Paredes de concreto moldada no local para a construção de edificação - Requisitos e procedimentos, Rio de Janeiro, Brasil.

Popescu, C., Sas G., Blanksvärd, T., Täljsten B. (2015), “Concrete walls weakened by openings as compression members: A review", Engineering Structures.89, 172-190.

Saheb, S.M., Desayi, P. (1990), "Ultimate strength of RC wall panels with openings", Journal of Structural Engineering. 116, 1565-1577.

Sajdlová, T. (2016), ATENA program documentation, Part 4-9,Cervenka Consulting, Prague, Czech Republic.

Silva, M.A., Diaz, R.A.S., Almeida, L.C., Trautwein, L.M. (2021), "Numerical analysis of RC wall with opening and strengthened with CFRP", IBRACON Structures and Materials Journal. 14

Todut, C., Dan, D., Stoian, V. (2015), "Numerical and experimental investigation on seismically damaged reinforced concrete wall panels retrofitted with FRP composites", Composite Structures. 119, 648-665.

van Mier, J.G.M. (1986), “Multiaxial strain-softening of concrete, part i: fracture”, Material and Structures. 19, 179-189. 